\title{
LA CONSTRUCCIÓN INTERACCIONAL DE NARRATIVAS DE FICCIÓN ENTRE NIÑOS DE DISTINTAS EDADES. UN ESTUDIO CON NIÑOS DE POBLACIONES URBANO MARGINADAS*
}

\author{
THE INTERACTIONAL CONSTRUCTION OF FICTIONAL NARRATIVES BETWEEN CHILDREN OF \\ DIFFERENT AGES. A STUDY WITH CHILDREN FROM MARGINALIZED URBAN POPULATIONS
}

\author{
FLORENCIA ALAM**
}

\begin{abstract}
*Trabajo realizado en el marco de los proyectos Aspectos lingüísticos y cognitivos del proceso de alfabetización de grupos en riesgo por pobreza: Niños, jóvenes y adultos analfabetos y minorías étnicas (PIP 2009-2011 № 112-200801-00834) del Consejo Nacional de Investigaciones Científicas y Técnicas (CONICET) y Aspectos lingüísticos y cognitivos del proceso de alfabetización de grupos en riesgo por pobreza: Niños, jóvenes y adultos analfabetos y minorías étnicas (PICT 2539/2010) de la Agencia Nacional de Promoción Científica y Tecnológica (ANPCYT).

${ }^{* *}$ Doctora en Educación y Licenciada en Letras. Becaria Doctoral del Consejo Nacional de Investigaciones Científicas y Técnicas (CONICET). E-Mail: florenciaalam@gmail.com Ávalos 1655, (C1431DPE) Ciudad Autónoma de Buenos Aires, Argentina.
\end{abstract}

\section{RESUMEN}

El estudio realizado se propuso analizar el proceso de construcción interaccional de narrativas de ficción por parte de díadas de niños de distintas edades (4 y 12 años) que viven en poblaciones urbano-marginadas de Argentina.

Las narrativas, elicitadas a partir de una secuencia de imágenes, fueron video-filmadas y luego transcriptas. El corpus incluye 33 relatos producidos por díadas de niños de 4 y 12 años. Se realizó un análisis cualitativo que combina el Método Comparativo Constante (Glaser \& Strauss, 1967; Strauss \& Corbin, 1990) con herramientas de la Sociolingüística Interaccional (Gumperz, 1982) y el Análisis de la conversación (Goodwin \& Heritage, 1990). Dicho análisis permitió generar un sistema de categorías que dio cuenta de los roles narrativos (Goodwin, 2007) asumidos por los participantes y el modo en que esos roles eran negociados en la interacción. Los resultados mostraron que los niños adoptaban diferentes roles narrativos que se configuraban a partir de una yuxtaposición de campos semióticos -verbales, gestuales y proxémicos-. Los niños pequeños adoptaban el rol de narrador o el rol de audiencia, mientras que los niños mayores asumían roles de tutor, narrador o audiencia. Asimismo, el análisis permitió mostrar cambios en los roles adoptados durante la situación de interacción. La relevancia de estudiar las narrativas producidas por niños pequeños en interacción con niños mayores reside justamente en los resultados de investigaciones previas (Stein \& Rosemberg, 2012) que señalan que en poblaciones urbanomarginadas las interacciones entre niños de distintas edades pueden dar lugar al aprendizaje y el desarrollo infantil.

Palabras clave: Interacciones entre niños; Construcción interaccional; Roles narrativos; Microanálisis de la interacción; Poblaciones urbanomarginadas.

\section{ABSTRACT}

This study aims to analyse the interactional construction of fictional accounts that 4-yearold and 12-year-old children from marginalized 
urban populations in Buenos Aires (Argentina) produced together. Recent research (Gardner \& Forrester, 2010; Rosemberg \& Menti, in press) suggests the need to link the study of child development and performance with the microanalysis of interaction. As these studies point out, the concepts developed by Conversation analysis (Goodwin \& Heritage, 1990; Sacks, Schegloff \& Jefferson, 1974) and Interactional Sociolinguistics (Gumperz, 1982) allow to study in detail the processes through which children and their partners construct shared meaning in interaction.

The narratives, elicited from a sequence of images, were video recorder and transcribed. The data corpus consist of 33 narratives produced by dyads of 4 and 12 year-old children. A qualitative analysis was performed that combined the Constant Comparative Method (Glaser \& Strauss, 1967; Strauss \& Corbin, 1990) with tools from Interactional Sociolinguistic (Gumperz, 1982) and Conversation Analysis (Sacks, Schegloff \& Jefferson, 1974). This analysis allowed the generation of a system of categories that identified the narrative roles assumed by the participants (Goodwin, 2007) and how these roles were negotiated in the interaction. Findings showed that children adopted narrative roles that were configured from a juxtaposition of information from different semiotic fields -verbal, gestural and proxemic-. 4-year-old children adopted roles of storyteller or audience, and 12-year-old children assumed roles of tutor, storyteller or audience. The tutor role was characterised by the initiations of the sequence employing elicitations. Also, tutors used different types of interventions -feedback, expansions and repairs- to scaffold the narrative elaborated by the young children. The body position, as well as the gaze of the tutor was directed to the story-teller and/or to the images, and also in some cases to the researcher. The storyteller role was characterised by giving verbal information about the narrative. The body position, as well as the gaze of the storyteller was directed principally to the audience and/or to the images. Finally, the audience role was characterised for showing interest in the narrative through different signals such as gaze direction to the storyteller, and a body position close to him and to the images. These results show the productivity of articulating the psycholinguistic perspective (Nelson, 1996, 2007) with tools of the Conversational Analysis (Goodwin \& Heritage, 1990) to account for narrative performance. Results showed that while the 12year-old children tended to adopt in most cases a tutor role, the 4-year-old assumed a storyteller role. The narrative roles adopted by the children show that children from different ages can negotiate narrative co-construction. However, in some cases both children adopted a storyteller role. In these situations the asymmetric relation between the 12-year-old and the younger child led the older child to impose his narrative not letting the 4-year-old to narrate.

The microanalysis of the interactional sequences showed that the roles adopted could change during the interaction. This role change did not occur randomly, but responding to the sequence of actions in which each participant analysed the contextualization cues (Gumperz, 1982) provided by the other and acted according to them. The analysis of the exchanges showed the complexity of the interactional process with regard to the construction of the stories, in which it is not possible to comprehend the actions of one participant without referring to the actions of the other (Goodwin, 1984).

The relevance of studying the narratives produced by young children interacting with older children lies in the results of previous studies (Stein \& Rosemberg, 2012) which reported that in urban marginalized populations interactions between children of different ages can lead to learning and child development.

Key words: Interaction between children; Interactional construction; Narrative roles; Microanalysis of interaction; Urban marginalised populations.

\section{INTRODUCCIÓN}

El estudio del proceso interaccional de construcción de una narrativa entre niños de distintas edades cobra especial importancia en el marco de investigaciones recientes (Gardner \& Forrester, 2010; Rosemberg, 2002; Rosemberg \& Menti, en prensa) que 
destacan la necesidad de articular el estudio del desarrollo y el desempeño infantil con el microanálisis de la interacción. Como señalan estas investigaciones, los conceptos desarrollados por el análisis de la conversación (Goodwin \& Heritage, 1990; Sacks, Schegloff \& Jefferson, 1974; Tuson, 1995) y la Sociolingüística interaccional (Eerdemans, Prevignano \& Thibault, 2003; Gumperz, 1982) permiten estudiar en detalle los procesos a través de los cuales los niños y sus interlocutores construyen significado de modo compartido en las situaciones de interacción.

El análisis conversacional (Goodwin \& Heritage, 1990; Sacks, Schegloff \& Jefferson, 1974; Tuson, 1995) define la conversación como una forma de discurso coproducida por dos o más interlocutores, que se organiza a partir de la alternancia de turnos, unidad básica de la organización conversacional. Los turnos no se suceden de forma aleatoria, sino que, como sostiene Tuson (1995), se estructuran a partir de la conformación de una secuencia. En efecto, la aparición de un turno se explica en función de los turnos precedentes y de los siguientes. Para explicar la conformación de una secuencia conversacional Goodwin y Heritage (1990) proponen el concepto de posición siguiente, según el cual las acciones realizadas por un participante proyectan una posible acción siguiente. En una interacción cada participante analiza las acciones de los otros para poder producir acciones que respondan a las realizadas previamente y que a la vez proyecten nuevas acciones.

Sinclair y Clouthard (1975) analizaron la secuencia conversacional típica de los intercambios escolares. Estos autores describieron una estructura tripartita: un movimiento de iniciación, un movimiento de respuesta y un movimiento complementario. Un participante -generalmente el maestro- inicia proporcionando o recabando información, un participante -generalmente un niño- responde y otro participante -generalmente el maestro- comenta la respuesta o evalúa su aceptabilidad o corrección. La definición de cada movimiento como iniciación, respuesta o movimiento complementario depende de su rela- ción con la estructura del intercambio $\mathrm{y}$, a su vez, informa a los participantes sobre cómo se espera que siga secuencialmente el discurso.

Desde la Sociolingüística interaccional, Gumperz (1982) sostiene que el contexto de las interacciones está conformado tanto por la organización de los turnos de habla, como por otra serie de aspectos claves que permiten que los interlocutores interpreten apropiadamente las expresiones en la conversación. En la interacción los participantes activan esquemas interpretativos que han desarrollado durante la socialización primaria. Estos esquemas les permiten interpretar las claves, que Gumperz (1982) denomina pistas de contextualización. Se trata de un proceso de producción e interpretación contextualizada de significados, mediante el cual los interlocutores establecen relaciones entre lo expresado en la situación de interacción con el conocimiento previo. El concepto de pistas de contextualización (Eerdemans et al., 2003; Gumperz, 1982) permite dar cuenta de cómo los participantes crean un contexto y guían a sus interlocutores hacia una interpretación apropiada de sus acciones verbales o no verbales. Los interlocutores en una conversación se apoyan en estas pistas para dar a conocer sus intenciones y para atribuir significado a lo que ven y oyen en los encuentros interactivos en los que participan. Las pistas de contextualización incluyen señales verbales y prosódicas, como así también la manipulación de objetos, los gestos, el registro, los cambios de código y la dirección de la mirada.

En su mayoría, los estudios que analizaron las interacciones entre niños (Coll, 1991; Doise, Muguy \& Perret-Clermont, 1975; Fawcett \& Garton, 2005; Forman \& Cazden, 1984; Mashburn, Justice, Downer \& Pianta, 2009; Mugny \& Pérez, 1988; Roselli, 1999, entre otros) no han analizado el proceso de negociación que se produce en la interacción, como así tampoco las habilidades discursivas que se ponen en juego en esa negociación. En efecto, aún cuando en muchos de estos estudios las tareas implican intercambios verbales entre los niños para arribar a la resolución, no se analizan los recursos lingüísticos y de otros campos semióticos a los 
que los niños recurren en la interacción con el objeto de alcanzar la comprensión mutua (Gumperz, 1982).

Si bien algunas investigaciones han empleado una metodología conversacional para analizar los modos de negociación que despliegan los niños en las interacciones con otros niños, estos trabajos se han centrado en interacciones entre niños de la misma edad, tanto en conversaciones espontáneas (Keenan, 1979) como en el contexto escolar (García Sánchez, 2010; Hamo \& Blum-Kulka, 2007; Unamuno, 2008), o en situaciones de juego (Goodwin, 2006; Goodwin, C., Goodwin, M. \& Yaeger-Dror, 2002; Migdalek \& Rosemberg, 2013).

Pocas investigaciones han adoptado una perspectiva conversacional para estudiar las interacciones entre niños de distintas edades. Éstas analizaron las interacciones en contextos escolares de tutoría (Alam, Stein \& Rosemberg, 2011; Rosemberg, Alam \& Stein, 2014) o los recursos discursivos empleados por los niños en la construcción de una narrativa (Alam \& Rosemberg, 2013). Hasta el momento no se han encontrado investigaciones que hayan estudiado el proceso a través del cual niños de distintas edades negocian y construyen una narrativa en interacción. Sin embargo, los estudios que desde el análisis de la conversación analizaron narrativas producidas en interacciones entre adultos, han mostrado la importancia de atender a la construcción interaccional de los relatos (Goodwin, $\mathrm{C}$. 1984, 2007; Goodwin, M., 1997).

Así por ejemplo, Goodwin (1984) estudió la organización interactiva que se desplegaba entre los participantes durante la narración de un evento por parte de uno de ellos. Utilizando un registro fílmico de una cena en la que participaban cuatro adultos, Goodwin analizó los roles narrativos que adoptaba cada uno de los participantes a partir de sus acciones y de las acciones que realizaban los otros. Identificó un rol de narrador, un rol de audiencia-destinatario, que se caracterizó por ser a quien el narrador se dirigía y por mantener la mirada dirigida al narrador, mostrando así su atención, y un rol de audienciano destinatario, que si bien participaba de la interacción no recibía la mirada del narrador y su atención estaba focalizada en otras actividades.

Goodwin (1984) mostró a través del análisis de las acciones que llevaba a cabo cada uno de los participantes, que la narración no era solo realizada por el hablante, sino a partir de una negociación entre todos los participantes de la interacción. En efecto, la manera en la que el narrador articulaba su habla y se posicionaba corporalmente permitía diferenciar segmentos y funcionaba de guía para las acciones que llevaban a cabo los participantes. A su vez, la dirección de la mirada de la audiencia y las acciones que ésta realizaba funcionaban como indicadores para el narrador de la atención que estaba recibiendo su relato, y de esa manera podía estructurar su narrativa.

Como señalan tanto Goodwin, M. (1997) como Goodwin, C. (1984, 2007), la elección de las acciones por parte de los receptores tiene consecuencias en la narrativa. Debido a ello, el análisis de las estructuras participativas durante la conversación tiene relevancia para la comprensión de la producción narrativa. La atención a los detalles referidos a cómo los receptores actúan en la conversación permite entender las narraciones en términos de eventos de habla construidos dinámicamente. A pesar de que un hablante pueda proponer una forma particular para que su discurso sea recepcionado, los receptores tienen múltiples formas de actuar a partir de lo que escuchan. En este sentido estos autores postulan la necesidad de reconceptualizar la noción de autoría en las interacciones, proponiendo como unidad de análisis los marcos participantes (Goodwin, C., 2003; Goodwin, M., 2006). Este concepto alude a la organización de la interacción como resultado de las acciones del hablante así como también del oyente o los oyentes.

Las narrativas infantiles han sido ampliamente abordadas por una serie de estudios que, desde una perspectiva psicolingüística y sociocultural (Nelson, 1996, 2007), se han focalizado en las narrativas producidas en situaciones de interacción niño-adulto (Fivush \& Haden, 2005; Fivush, Haden \& Reese, 
2006; Haden, Haine \& Fivush, 1997; Melzi, 2000; Sparks, Carmiol \& Ríos, 2013, entre otros). Los resultados de estos estudios mostraron que los adultos utilizan estrategias para andamiar la producción de las narraciones infantiles, ayudándolos a organizar los relatos causal y temporalmente, como así también a construir evaluaciones en relación al evento narrado.

Algunas de estas investigaciones han estudiado los diferentes estilos maternos de interacción (Fivush, 2007; Reese, Haden \& Fivush, 1993). Así por ejemplo, Melzi y Caspe (2005) se focalizaron en los estilos maternos de interacción durante la producción de relatos de ficción a partir de un libro de imágenes. En su estudio compararon los relatos producidos por 31 madres peruanas y estadounidenses en interacción con sus hijos de 3 años. Se identificaron en las madres dos estilos diferentes, un estilo narrador, en el que la madre narraba con poca participación del niño, focalizándose en los eventos que presentaban las imágenes y un estilo constructor, en el que la madre co-construía el relato con el niño, incluyendo experiencias del niño y conocimiento sobre eventos generales. La comparación entre los dos grupos mostró que las madres peruanas, en su mayoría, adoptaban un estilo narrador y las madres estadounidenses adoptaban un estilo constructor.

Las investigaciones mencionadas, llevadas a cabo con poblaciones de sectores medios, se han focalizado en el impacto de la interacción de la madre en el desempeño narrativo del niño pequeño tomando como referencia el modelo predominante en las familias de estos sectores sociales, que considera a la díada madre-niño como el núcleo del desarrollo. Sin embargo, otros trabajos que estudian el aprendizaje infantil en grupos indígenas y urbano-marginados (Rogoff, 1993, 2003; Rosemberg, Stein \& Alam, 2013; Stein \& Rosemberg, 2012) han señalado que en estos contextos culturales las interacciones entre niños tienen una importante relevancia para el desempeño y el desarrollo de los pequeños.

Es por ello que el que el objetivo del estudio que se informa fue analizar el proceso de negociación y construcción de una narrativa de ficción elicitada por medio de una secuencia de imágenes a díadas de niños de 4 y 12 años de barrios urbano-marginados de la Provincia de Buenos Aires (Argentina).

\section{MÉTOdO}

CORPus

El corpus de datos analizado incluye 33 narrativas elicitadas por medio de una secuencia de imágenes a 33 díadas de niños y niñas de 4 y 12 años. La conformación de cada díada se realizó al azar.

\section{PARTICIPANTES}

Los niños que participaron en este estudio viven en poblaciones en situación de pobreza. Se trata de poblaciones caracterizadas por la presencia de viviendas precarias, pequeñas y con infraestructura insuficiente. Las familias que las conforman son migrantes recientes o descendientes de migrantes provenientes de provincias del norte de Argentina o de países limítrofes y/o cercanos, principalmente: Bolivia, Paraguay y Perú. En su mayoría, son familias numerosas cuya transición al medio urbano local se caracteriza no sólo por la hibridación de pautas culturales de origen sino también porque su vida cotidiana transcurre en situación de indigencia y pobreza extrema.

\section{MATERIALES}

Las narrativas se elicitaron a partir de una secuencia de imágenes que recuperaba el contexto de un evento, en este caso fue una visita a un museo etnográfico, al que todos los niños habían asistido conjuntamente.

La secuencia de ilustraciones cuenta la historia de dos niños, uno grande y otro pequeño que van de visita a un museo, allí los dos niños observan los objetos, el niño más grande se detiene a mirar una vasija y el pe- 
queño, una máscara. Al niño pequeño se le ocurre una idea: toma la máscara, se la pone y asusta a su compañero. Luego se saca la máscara y ambos se ríen de la broma del pequeño. Una maestra llega y reta al niño pequeño por tocar los objetos del museo. La secuencia de imágenes se presenta en el Anexo 1.

\section{Procedimiento}

OBTENCIÓN DE LA INFORMACIÓN EMPÍRICA

Se entrevistó a las parejas en un aula de la escuela y sus narraciones fueron video-grabadas. Los niños se sentaban uno al lado del otro y la investigadora se ubicaba de frente a ellos. Atrás de la investigadora se encontraba, a la vista de los niños, una cámara fija que permanecía prendida desde que ingresaban a la sala hasta que se iban.

La investigadora les entregaba la secuencia de imágenes y les decía que miraran las imágenes y contaran el cuento todas las veces que quisieran, y que cuando terminaran la llamaran. Luego se retiraba de la sala. Una vez que los niños la llamaban, ella escuchaba el relato con las imágenes a la vista tanto de los niños como de ella sin realizar preguntas.

Se optó por el uso de video filmaciones en tanto que permiten captar de un modo abierto no estructurado la información empírica que configura las narraciones en la interacción. Estas técnicas posibilitan una aproximación ecológica a las características de los comportamientos verbales y no verbales que permiten la construcción interaccional de las narraciones (Duranti, 1997).

\section{TRANSCRIPCIÓN}

Las video-grabaciones fueron transcriptas para su análisis, realizando una desgrabación literal de los archivos de audio. Los registros fueron complementados con la información del contexto situacional y comportamientos no verbales registrados en los videos. Las transcripciones se realizaron de acuerdo a las codificaciones que se presentan en el Anexo 2.

\section{ANÁLISIS DE LA INFORMACIÓN EMPÍRICA}

Se realizó un análisis cualitativo del proceso de construcción interaccional de las narrativas que combina el Método Comparativo Constante (Glaser \& Strauss, 1967; Strauss \& Corbin, 1991) con herramientas de la Sociolingüística Interaccional (Gumperz, 1982) y del Análisis de la Conversación (Goodwin, 1984, 2007; Sacks et al., 1974). Dicho análisis permitió generar un sistema de categorías que dio cuenta de: (a) los roles narrativos que adoptan los niños mayores; (b) los roles narrativos que adoptan los niños pequeños; (c) la yuxtaposición de distintos campos semióticos -la información lingüística, la posición corporal, la entonación, la orientación de la mirada, los gestos y la manipulación de los objetos presentes en el entorno- que les permite a los participantes negociar la construcción conjunta de las narrativas.

En un segundo momento, se cuantificó el porcentaje de cada rol adoptado por los niños pequeños y los mayores con el objeto de conocer su distribución en el corpus. Para ello se consideraron únicamente los roles que los niños asumían al comienzo del intercambio.

\section{Resultados}

El análisis de las interacciones entre los niños pequeños y los mayores puso de manifiesto que para construir una narrativa los niños adoptaban diferentes roles que se configuraban a partir de una yuxtaposición de campos semióticos (verbales, gestuales y proxémicos). Los niños pequeños adoptaban el rol de narrador o de audiencia, mientras que los niños mayores asumían roles de tutor, narrador o audiencia.

Se consideró que un niño mayor adoptaba el rol de tutor en los casos en los que iniciaba las secuencias por medio de elicitaciones y se valía de diversos tipos de intervenciones- retroalimentaciones, expansiones y reparaciones- para andamiar la elaboración de la narrativa por parte del niño pequeño. La posición corporal, así como la mirada del tutor, se dirigían al narrador y/o a las imágenes, 
así como también en algunos casos a la investigadora. Por su parte, se consideró que un niño mayor o pequeño asumía el rol de narrador cuando aportaba de forma verbal información sobre la narrativa. La posición corporal y la mirada del narrador se dirigían principalmente a la audiencia y/o a las imágenes. Por último, se consideró que un niño, ya fuese de 4 ó 12 años, adoptaba el rol de audiencia cuando no aportaba información verbal a la narrativa, sino que señalaba interés en el relato de su compañero a través de diversos indicadores tales como el mantenimiento de la mirada al narrador, una posición corporal próxima a él y a las imágenes, así como asentimientos relacionados con la narrativa.

Se presenta un ejemplo en el que es posible observar el rol de tutor adoptado por el niño mayor y el rol de narrador adoptado por el niño pequeño:

\author{
Ejemplo 1: Ariel (4 años) y Emir (12 años) \\ \{Ariel está apoyado contra el respaldo de \\ la silla, mira hacia las imágenes o hacia Emir. \\ Emir se encuentra inclinado hacia Ariel y \\ apoya los brazos sobre la mesa, alterna la \\ mirada entre Ariel y la investigadora. Las \\ imágenes se encuentran frente a Ariel $\}$ \\ 1 EMIR: bueno |quiénes son ellos / \\ 2 ARIEL: ${ }^{\circ}$ Ariel y $\mathrm{Facu}^{\circ}$ । \\ 3 EMIR: Ariel y Facu | adónde están en- \\ trando/ \\ [mira a INVESTIGADORA] \\ [mira a ARIEL] \\ 4 ARIEL: ${ }^{\circ}$ al museo $^{\circ}$ \\ [mira a EMIR] \\ 5 EMIR: al museo $\backslash(($ pasa la hoja $))$ qué está \\ haciendo Ariel/ \\ [mira a INVESTIGADORA] \\ [mira a ARIEL] \\ 6 ARIEL: ${ }^{\circ}$ mirando la máscara ${ }^{\circ} \backslash$ \\ [mira a EMIR] \\ 7 EMIR: $y$ Facu/ \\ [mira a ARIEL] \\ 8 ARIEL: ${ }^{\circ}$ mirando una vasica ${ }^{\circ} \mid$ \\ [mira a EMIR] \\ 9 EMIR: una vasica \\ [mira a INVESTIGADORA]
}

Como se pone de manifiesto en el ejemplo 1, Emir, el niño mayor, conduce a través de preguntas, gestos deícticos y el pasaje de las imágenes, la narrativa. Emir inicia las secuencias a través de una elicitación - turno 1 , bueno \quiénes son ellos/; turno 5, qué está haciendo Ariel/ -, a las que Ariel responde proporcionando la información solicitada turno 2, ${ }^{\circ}$ Ariel y Facu 9; turno 6, ${ }^{\circ}$ mirando la máscara $^{\circ}$ - y que luego Emir retroalimenta a través de una repetición de la emisión producida por el pequeño -turno 5, al museol-. Cabe señalar que cuando Emir repite las emisiones de Ariel lo hace dirigiendo la mirada a la investigadora -turno 3, 5, 9 [mira a INVESTIGADORA]-. Es posible que estas repeticiones no solo sean utilizadas como un modo de retroalimentación, sino también para dirigirse a la audiencia. Esto podría deberse a que Ariel utiliza un volumen de voz muy bajo (marcado en la transcripción por los signos ${ }^{\circ}$ o) y no dirige la mirada en ningún momento a la investigadora. Emir, a través de estas repeticiones en un volumen más alto y de la dirección de la mirada, construye a la investigadora en audiencia de la narrativa que ambos elaboran. Cabe señalar que el tutor establece esta distribución de roles (tutorEmir y narrador-Ariel le relatan el cuento a la audiencia-investigadora) al principio de la interacción. En efecto, antes de comenzar la secuencia presentada en el ejemplo 1, Emir le propone a Ariel contarle juntos el cuento a la investigadora. En este sentido, y teniendo en cuenta que la tarea solicitada es justamente relatarle el cuento a la investigadora, la repetición de las intervenciones poco audibles de Ariel, sumado a una dirección de la mirada que muestran hacia quién está dirigido el relato, pueden entenderse como un intento del niño mayor por llevar a cabo la tarea. Este intento debe ser entendido teniendo en cuenta que el niño pequeño proporciona determinadas pistas de contextualización -un tono casi inaudible y la no dirección de la mirada a la audiencia- que se podrían interpretar como un deseo de no participar.

En otras situaciones en las que, al igual que en el intercambio entre Ariel y Emir, el niño mayor adoptaba un rol de tutor y el pe- 
queño un rol de narrador, era el niño pequeño el que construía a la investigadora en audiencia, alternando para ello la mirada entre el tutor, a quien respondía las preguntas, y la audiencia a quien le dirigía el relato, tal como se muestra en el fragmento de intercambio entre Cristian y Candela:

Ejemplo 2: Candela (4 años) y Cristian (12 años)

\{Cristian está sentado de costado en la silla dirigiendo su cuerpo a Candela. Candela se encuentra de frente a la mesa y alterna la mirada entre Cristian, las imágenes y la investigadora. Las imágenes se encuentran frente a Candela\}

1 CRISTIAN: para vos Candela qué están haciendo ellos/ [mira a CANDELA]

2 CANDELA: observandol

[mira a IMAGEN]

[mira a INVESTIGADORA]

3 CRISTIAN: observando la máscara la vasija 1

[mira a CANDELA]

4 CANDELA: ((pasa la hoja))

5 CRISTIAN: $y$ acá / ((señala al personaje)) qué está haciendo /

[mira a CANDELA]

6 CANDELA: se le ocurrió una idea para asustar al hermano I

[mira a INVESTIGADORA]

[mira a CRISTIAN]

[mira a INVESTIGADORA]

7 CRISTIAN: una idea $\backslash$ y el hermano ((señala al personaje)) sigue viendo la vasija I

Como se muestra en el Ejemplo 2 Cristian adopta un rol de tutor que se pone de manifiesto en el inicio de las secuencias, -turno 1, para vos Candela qué están haciendo ellos/; turno 5, y acá / ((señala al personaje)) qué está haciendo/- y en la retroalimentación de las respuestas de Candela, en las que expande sus intervenciones -turno 3, observando la máscara la vasijal; turno 7, una idea y el hermano ((señala al personaje)) sigue viendo la vasijal-. Sin embargo, a diferencia del intercambio entre Ariel y Emir, en este caso es
Candela la que manipula el libro -turno 4, ((pasa la hoja))- y la que construye el rol de audiencia en la investigadora, a través de la dirección de la mirada al final de sus intervenciones -turno 2, turno 6, [mira a INVESTIGADORA]-. Por su parte, Cristian, a diferencia de Emir, no dirige en ningún momento la mirada a la investigadora. En este sentido, las acciones de Emir o de Cristian, deben entenderse en relación con las acciones de Ariel o de Candela, y lo mismo de modo inverso. Esta negociación entre los participantes, que no se da a través solo de las intervenciones verbales, sino a través de una compleja red de campos semióticos que incluyen tanto lo verbal como la mirada, la posición corporal, el volumen de la voz y el uso de los materiales, permite que los niños construyan una narrativa colaborativa.

En algunas interacciones fue posible observar cambios durante la interacción en los roles adoptados por los niños. Así por ejemplo, se encontró que en ocasiones los niños mayores adoptaban en un primer momento un rol de tutor y luego, a medida que avanzaba el relato dejaban que el pequeño continuase solo, adoptando así un rol de audiencia.

Ejemplo 3: Sebastián (4 años) y Erica (12 años)

\{Erica se sienta con el torso dirigido a Sebastián, y éste a su vez se dirige corporalmente a Erica. Las imágenes se encuentran entre ambos niños\}

1 ERICA: a dónde entraron/

2 SEBASTIÁN: al museo $\mid$

3 ERICA: y qué vieron/((señala la máscara))

4 SEBASTIÂN: una vasija y una máscara $\mid$ [mira a ERICA]

5 ERICA: ((pasa la hoja))

6 SEBASTIÁN: ((se incorpora en la silla y acomoda el libro))

7 ERICA: y el nene qué pensó/

8 SEBASTIÁN: los dos ((señala a los dos personajes)) estaban mirando la vasija $\mid$

[mira a ERICA]

9 ERICA: pero el chiquito ((señala al chico)) qué pensól

10 SEBASTIÁN: que:: podí::a- 
11 ERICA: ((señala la máscara))

12 SEBASTIÁN: ((señala la máscara)) agarrar la máscara $\mid$

13 ERICA: y lo iba a asustar al más grande no/ ((comienza a pasar la hoja))

14 SEBASTIAN: sí ((agarra la hoja y acompaña el movimiento de ERICA))

15 SEBASTIÁN: y agarró la máscara $\mid$

16 ERICA: agarró la máscara 1

17 ERICA: ((pasa la hoja)) y qué pasó/

18 SEBASTIÁN: lo asustó el más chiquitol y el nene se asustó $\mid$ ((agarra la punta de la hoja))

19 ERICA: ((agarra la punta de la hoja))

20 SEBASTIÁN: ((agarra la hoja y la pasa))

21 SEBASTIÁN: y después se murieron de risal

[mira a INVESTIGADORA]

22 ERICA: \{ríe\}

23 SEBASTIÁN: porque era él \((señala al chico))

[mira a INVESTIGADORA]

24 ERICA: porque era él $\backslash($ (señala al chico)) [mira a SEBASTIÁN]

25 SEBASTIÁN: ((pasa la hoja)) y acá la chica lo reto porque tocó la- ((señala la máscara)) al chiquito la señora ((señala a la maestra)) lo reto porque toco esto \((señala la máscara))

[mira a INVESTIGADORA]

En el intercambio que se presenta en el Ejemplo 3, Erica adopta un rol de tutora, inicia las secuencias por medio de preguntas -turno 3, y qué vieron/- y gestos deícticos -turno 11, ((señala la máscara))-, que se apoyan en las imágenes para elicitar el relato por parte de Sebastián. Asimismo, la niña-tutora retroaliementa las respuestas del niño pequeño -turno 16, agarró la máscara-, pidiendo en algunos casos mayor información -turno 9, pero el chiquito qué pensó/-, o agregando la que el niño no proporciona -turno 13, y lo iba a asustar al más grande- y gestiona los tiempos del relato a través del pasaje de las hojas -turno 5, ((pasa la hoja))-.

A medida que avanza el relato, Sebastián comienza a participar en el pasaje de las hojas, primero acomodando el libro una vez que Erica cambió la hoja -turno 6-, luego participa en el pasaje de la hoja junto con Erica -turno 14- y hacia el final del relato, es el niño pequeño el que pasa la hoja. Este cambio en el manejo del material, que puede interpretarse como una demostración de mayor autonomía del niño pequeño, también puede verse en el inicio de las secuencias, mientras que las primeras secuencias son todas iniciadas por Erica, en el turno 15 Sebastián inicia la secuencia -y agarró la máscaraCabe señalar que el niño al iniciar la secuencia lo hace utilizando el conector aditivo " $y$ ". Esta elección podría deberse a un intento por marcar una continuidad con lo dicho anteriormente. Sin embargo, si se observa que Erica inicia las secuencias de la misma manera -turno 3, y qué vieron/; turno 7, y el nene qué pensó/- es posible pensar que la adopción de un inicio similar al de su compañera, sumado a la mayor participación en la manipulación del material, podrían estar marcando un cambio en los roles narrativos, ya no entre tutor y narrador, sino entre narrador y audiencia.

Sin embargo, Erica vuelve a iniciar la secuencia siguiente -turno 17, y qué pasó/- y a manipular el material. Cabe señalar que la pregunta con la que inicia la secuencia es distinta a las preguntas anteriores. En efecto, mientras que las preguntas anteriores -turnos $1,3,7$ - son preguntas que focalizan, $\mathrm{o}$ bien a través del pronombre -adónde entraron/- o del verbo empleado -y qué vieron/y el nene qué pensó/- un aspecto particular de la imagen, o bien a través del uso de gestos deícticos que proporcionan la respuesta -y qué vieron/ ((señala la máscara))-, la pregunta de Erica en el turno 17 es una pregunta general sobre la imagen que no proporciona guías verbales o no verbales. En este sentido, si bien la niña mayor inicia la secuencia, funcionando así como una tutora, no proporciona el mismo nivel de ayuda que en las otras secuencias. Es posible pensar que de este modo Erica está evaluando y/o estimulando la autonomía de Sebastián para narrar sin su ayuda. En efecto, en las secuencias siguientes -turno 18 a 25-Sebastián narra de forma autónoma, manipulando las imágenes 
solo, y dirigiendo su mirada a la investigadora-audiencia.

Así como los tutores podían cambiar a un rol de audiencia -tal como en el intercambio entre Sebastián y Erica- cuando los niños mayores adoptaban al comienzo un rol de audiencia también podían cambiar durante la interacción a un rol de tutor con el objeto de andamiar la producción del niño pequeño, del modo en el que se pone de manifiesto en el siguiente fragmento de intercambio entre Joaquín (4 años) y Lucas (12 años):

Ejemplo 4: Joaquín (4 años) y Lucas (12 años)

$\{$ La investigadora ingresa a la sala $\}$

1 JOAQUÍN: ya terminamos

2 INVESTIGADORA: bueno me lo van a contar a mi entonces ahora /

\{JOAQUÍN comienza a narrar sin mirar las imágenes. Su posición corporal y su mirada se dirigen a la investigadora. Lucas se sienta reclinado hacia atrás con el torso y la mirada dirigidos a Joaquín?

3 JOAQUÍN: después estaban yendo al museo $\backslash$ después estaban viendo (0.1) y después((apoya la cabeza sobre los puños cerrados y mira hacia abajo))

\{Lucas inclina el torso hacia adelante acercándose a Joaquín

4 LUCAS: ((señala las imágenes)) acáldónde iban Joaquín/

\{Joaquín se acerca a Lucas y mira las imágenes $\}$

5 JOAQUÍN: al museo 1

6 LUCAS: al museo 1

((pasan juntos la hoja))

\{Lucas se retira levemente hacia atrás. Mantiene la mirada dirigida a Joaquín

8 JOAQUÍN: acá estaban mirando ((pasa la hoja)) acá estaba- el nenito chiquitito ((señala al personaje)) estaba por agarrar la máscara ((pasa la hoja)) y ya la agarról

Cuando comienza la interacción, Joaquín adopta un rol de narrador y Lucas de audiencia. En efecto, el niño pequeño se ubica de frente a la investigadora, le dirige la mirada e inicia la secuencia. Por su parte Lucas permanece callado y se posiciona de frente a Jo- aquín dirigiéndole la mirada. Sin embargo, a los pocos segundos de comenzar el relato Joaquín se detiene, permanece en silencio y apoya la cabeza sobre los puños cerrados -turno 3-, probablemente dando a entender que no sabe cómo proseguir su relato. Lucas entonces adopta un rol de tutor, le acerca el libro y le formula una pregunta -turno 4, acál dónde iban Joaquín/- que le permite al niño continuar narrando. Joaquín parecería aceptar la intervención de Lucas, ya que no solo le responde, sino que también cambia su posición corporal acercándose a su compañero. Lucas retroalimenta la respuesta de Joaquín a través de una repetición -turno 6, al museoly luego deja que el pequeño continúe el relato, volviendo a adoptar un rol de audiencia.

En otros casos los niños no lograban negociar la construcción de la narrativa, como se muestra en el fragmento de intercambio entre Sabrina (4 años) y Carolina (12 años):

Ejemplo 5: Sabrina (4 años) y Carolina (12 años)

\{Carolina está sentada de frente a Sabrina y le dirige la mirada. Sabrina permanece sentada de frente a la mesa dirigiendo su mirada a la investigadora. Las imágenes están frente a Carolina\}

1 CAROLINA: había una vez un nene ((señala la imagen)) que iba al museo con su hermano más grandel lo que nosotros vimos no/ [mira a SABRINA]

2 SABRINA: $s i \backslash$

[mira a INVESTIGADORA]

3 CAROLINA: ((pasa la hoja))

4 CAROLINA: que cuando llegaron al museo vieron vasijas y máscaras y muchas cosas $\backslash$

[mira a IMAGEN][mira a SABRINA]

5 SABRINA: $m m j \backslash$

[mira a INVESTIGADORA]

6 CAROLINA: ((pasa la hoja))

7 CAROLINA: $y$ el nene pensaba si con esa máscara ((señala la máscara)) que lo iba a asustar al hermano más grande mientras él estaba mirando las vasijas $\backslash$

[mira a SABRINA]

8 SABRINA: $\mathrm{mmj} \backslash$

[mira a INVESTIGADORA] 
9 CAROLINA: estaba tan concentrado que dijo y yo lo voy a asustar a ver qué hace $\backslash$ [a IMAGEN][mira a SABRINA]

\{Sabrina agarra la hoja y comienza a levantarla. Carolina apoya el dedo pulgar sobre la hoja\}

10 CAROLINA: $=(($ agarra la hoja y la pasa) $=$

11 SABRINA: $=(($ agarra la hoja y la pasa $))=$ 12 SABRINA: y se pu- ((señala la máscara)) 13 CAROLINA: se puso la máscara $\mid$ 14 CAROLINA: ((agarra la hoja y la pasa)) 15 SABRINA: $=$ lo asustó $=$ [mira a INVESTIGADORA 16 CAROLINA: $=y$ y lo $=$ asustó al hermano $\backslash$

El Ejemplo 5 muestra un intercambio en el que ambas niñas adoptan el rol de narradora sin llegar a negociar la construcción conjunta del relato. La falta de acuerdo se pone de manifiesto a través de varias pistas de contextualización: la manipulación del libro que da cuenta de un control de los tiempos del relato, la superposición de turnos turno 15 y 16,= Sabrina: =asustó=, Carolina: $=y$ y y $l o=-$, la interrupción del turno -turnos 12, Sabrina: y se pus--, y la dirección de la mirada. En efecto, mientras que Carolina, la niña mayor, dirige la mirada a Sabrina, a quien busca ubicar así en el lugar de audiencia, la niña pequeña elude la mirada y la dirige a la investigadora. Un tutor no exige que la mirada esté dirigida a él, sino al objeto foco del aprendizaje, pero un narrador sí lo hace. En el intercambio analizado, Sabrina rompe esta regla mostrando su rechazo a ser ubicada como audiencia. Al hacerlo, el tercer participante, la investigadora, cobra especial importancia, en tanto que le permite a la niña pequeña construir otra audiencia para ubicarse ella misma en el lugar de narradora. En este sentido, es importante destacar que las interacciones aquí analizadas no son entre dos participantes, sino entre tres, ya que aún cuando sus intervenciones verbales sean mínimas y se reduzcan a proponer la tarea y darla luego por finalizada, la investigadora cumple un rol de audiencia.
El Gráfico 1 pone de manifiesto que los niños mayores adoptan en mayor medida un rol de tutor $(52 \%)$, en segundo lugar un rol de audiencia $(27 \%)$ y en menor medida un rol de narrador $(21 \%)$. Por su parte, el Gráfico 2 muestra que en la mayoría de los casos los niños pequeños adoptaban un rol de narrador $(88 \%)$ y en muy pocos casos de audiencia $(12 \%)$.

\section{DIscusión}

El análisis de la construcción interaccional de las narrativas puso de manifiesto que para lograr conformar una narrativa los niños adoptaban diferentes roles narrativos (Goodwin, 1984) que se configuraban y se negociaban a partir de una red compleja de información de distintos campos semióticos que incluía tanto lo verbal como la mirada, la posición corporal, el volumen de la voz y el uso de los materiales y objetos presentes en la situación (Goodwin, C., 1984, 2007; Goodwin, M., 1997).

En consonancia con el análisis de las narrativas entre madres y niños llevado a cabo por Melzi y Casper (2005) se identificaron para los niños mayores, roles de narrador y de tutor. Sin embargo, a diferencia de dicho trabajo, en el estudio realizado también se identifícó un rol de audiencia. Es posible que esta diferencia se debiera a que, como sostienen Hamo y Blum-Kulka (2007), las interacciones entre niños, aún cuando sean entre distintas edades, presentan una estructura más igualitaria que entre adultos y niños permitiendo que los niños mayores no siempre asumiesen un rol conductor como el de narrador o tutor, dejando lugar para que el niño pequeño narrase de forma más autónoma.

El análisis cuantitativo de los roles adoptados por los niños mostró que los niños pequeños adoptaban en la mayoría de los casos roles de narradores y los mayores, roles de tutores. En los casos en los que los mayores adoptaban un rol de tutor, la interacción asumía la forma de la secuencia tripartita propia del discurso escolar señalada por Sinclair y Clouthard (1975). En efecto, los tutores ini- 
ciaban las secuencias, generalmente a través de elicitaciones, los pequeños respondían y luego los mayores retroalimentaban sus respuestas.

El análisis de las interacciones puso de manifiesto diferencias entre los intercambios en la dirección de la mirada, la manipulación de las imágenes y la posición corporal aún cuando los niños asumieran los mismos roles. Así por ejemplo, se encontró que en algunos casos los niños que asumían el rol de tutor dirigían la mirada tanto a la investigadora-audiencia como al niño narrador y pasaban las hojas del libro, mientras que en otros casos era el niño-narrador el que manipulaba el material y construía la audiencia a través de la dirección de la mirada. Como se puso de manifiesto en el análisis, estas diferencias respondían a las acciones provistas por los otros participantes y eran negociadas en la interacción. En este sentido es posible pensar las diferencias en función de lo que Goodwin, C. (2003) y Goodwin, M. (2006) denominan marcos participantes y no como acciones aisladas de cada uno de los participantes.

El microanálisis de las secuencias interaccionales permitió mostrar que los roles adoptados podían cambiar a lo largo de la interacción. Así por ejemplo se identificó que en algunos casos los niños mayores comenzaban asumiendo un rol de tutor y luego, hacia el final del intercambio, adoptaban un rol de audiencia. En otros casos se encontró que al comienzo del intercambio el niño mayor adoptaba un rol de audiencia y durante el relato cambiaba a un rol de tutor. Como se mostró en el análisis, el cambio de rol no se daba de forma aleatoria, sino que respondía a la secuencia de acciones en la que cada participante interpretaba las pistas de contextualización (Gumperz, 1982) provistas por el otro y actuaba en función de las mismas.

En algunos casos tanto el niño mayor como el niño pequeño asumían roles de narrador. En estas situaciones la relación asimétrica entre el niño de 12 años y el pequeño generaba que el niño mayor impusiese su relato no dando lugar a que el niño pequeño narrara. Uno de los modos que utilizaban los niños pequeños para señalar su falta de acuerdo en estas situaciones era a través de la dirección de la mirada. En efecto, los niños pequeños no miraban al narrador, dando a entender que no asumían el rol de audiencia que el niño mayor buscaba otorgarles. Como señala Goodwin (1984), en determinados grupos culturales una de las reglas principales entre narradores y audiencia es la reciprocidad de la mirada, si el hablante mira al receptor éste debe devolverle la mirada. En este sentido, la falta de reciprocidad en la mirada puede constituir un indicador de la no ratificación del rol asumido por su interlocutor.

Aunque los conceptos desarrollados en este estudio pueden permitir la comprensión de otras situaciones de interacción, los resultados no son generalizables en tanto que se analizaron pocos casos. En este sentido, en investigaciones futuras sería interesante ampliar la muestra.

La mayoría de las investigaciones que estudiaron las interacciones entre niños se focalizaron en el resultado de la interacción y no en el proceso de negociación que despliegan los niños en la interacción (Coll, 1991; Doise et al., 1975; Fawcett \& Garton, 2005; Forman \& Cazden, 1984; Mashburn et al., 2009; Mugny \& Pérez, 1988; Roselli, 1999). El aporte del estudio realizado reside precisamente en el análisis que se realiza del proceso de negociación a través del cual los niños adoptan distintos roles narrativos que les permiten construir una narrativa de ficción.

La importancia de conocer el modo en el que niños de diferentes edades construyen una narrativa en interacción puede ponderarse apropiadamente si se considera en el marco de las investigaciones antecedentes que destacaron la importancia de la interacción para el desarrollo narrativo (Fivush \& Haden, 2005; Fivush et al., 2006; Haden et al., 1997; Melzi, 2000; Sparks et al., 2013). En efecto, estos trabajos realizados en situaciones de interacción niño-adulto, mostraron que los adultos andamian a través de variadas estrategias las narrativas infantiles. A diferencia de las invetigaciones mencionadas, en el estudio que se informa los niños no interactuaban con un adulto, sino con un niño mayor. La relevancia de analizar las 
narrativas producidas por niños pequeños en interacción con niños mayores reside justamente en los resultados de investigaciones previas (Rosemberg et al., 2013; Stein \& Rosemberg, 2012) que señalaron que en poblaciones urbano-marginadas, como la del presente estudio, las interacciones entre niños de distintas edades pueden dar lugar al aprendizaje y el desarrollo infantil. Asimismo, otras investigaciones también seña- laron la importancia de las interacciones entre niños en comunidades indígenas (Rogoff, 1993, 2003). En este sentido, en investigaciones futuras sería interesante ampliar la población en estudio a otros grupos socioculturales a fin de contemplar eventuales diferencias socioculturales en la producción de narrativas entre niños de distintas edades.

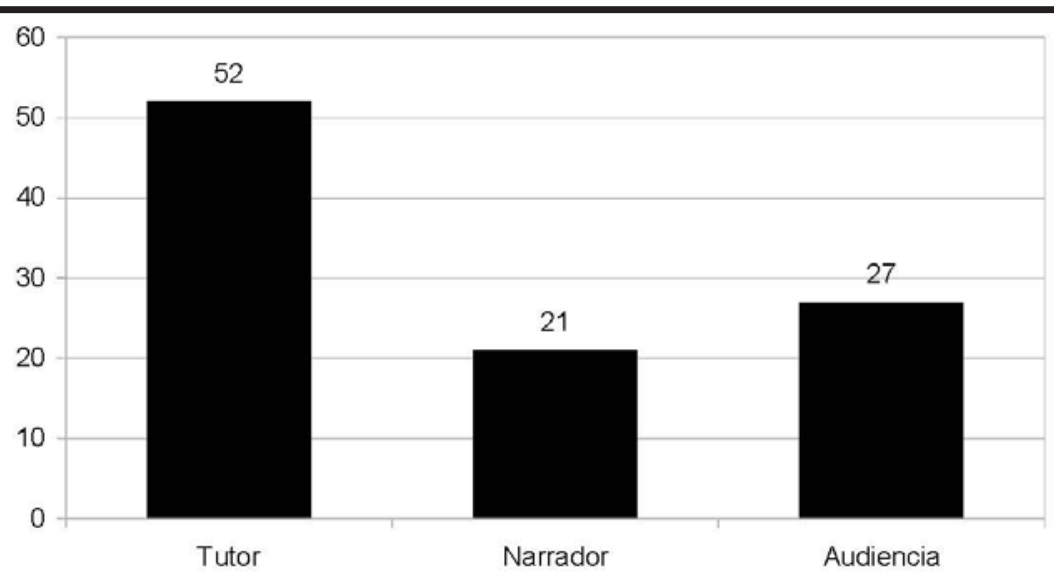


Alam

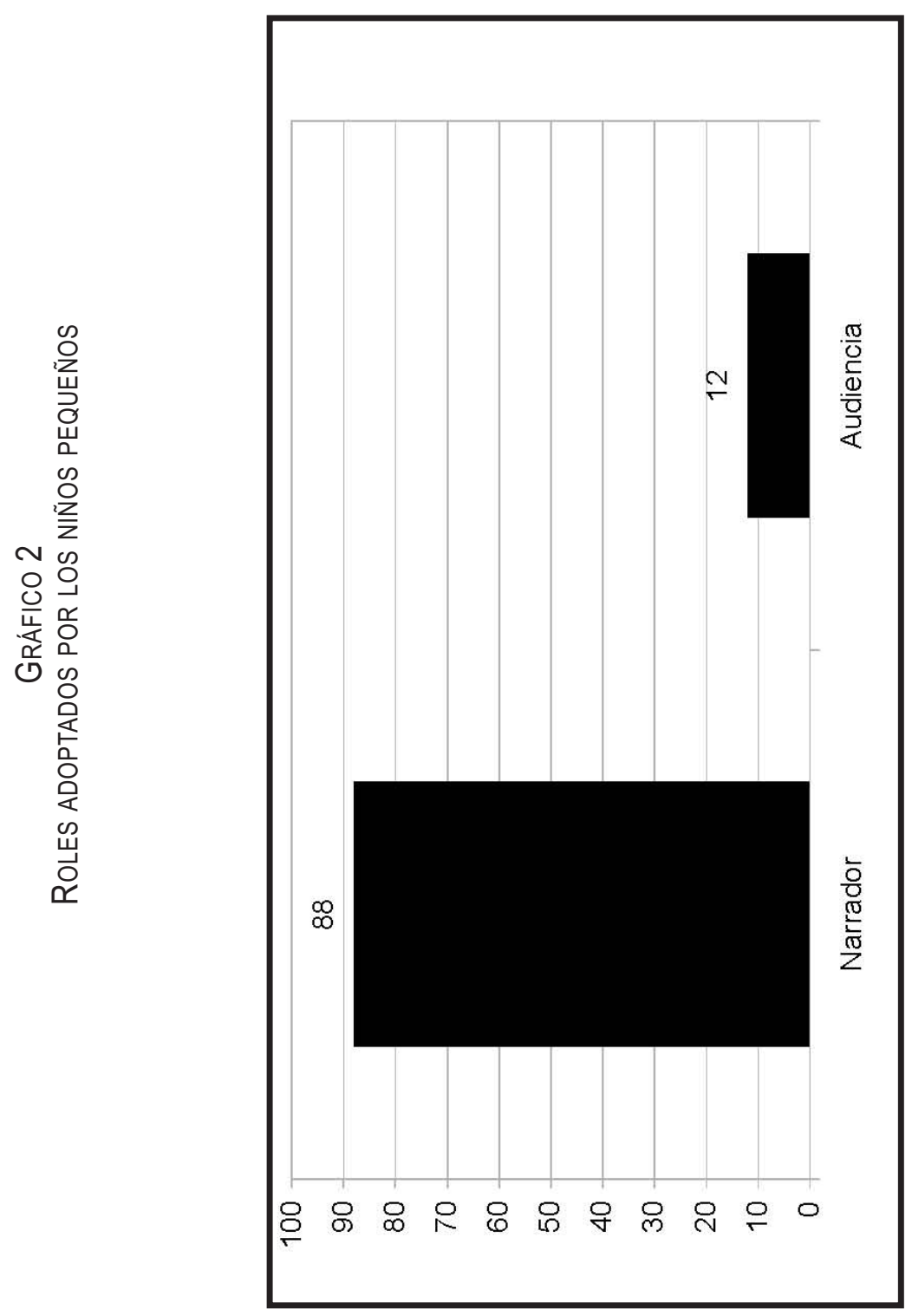



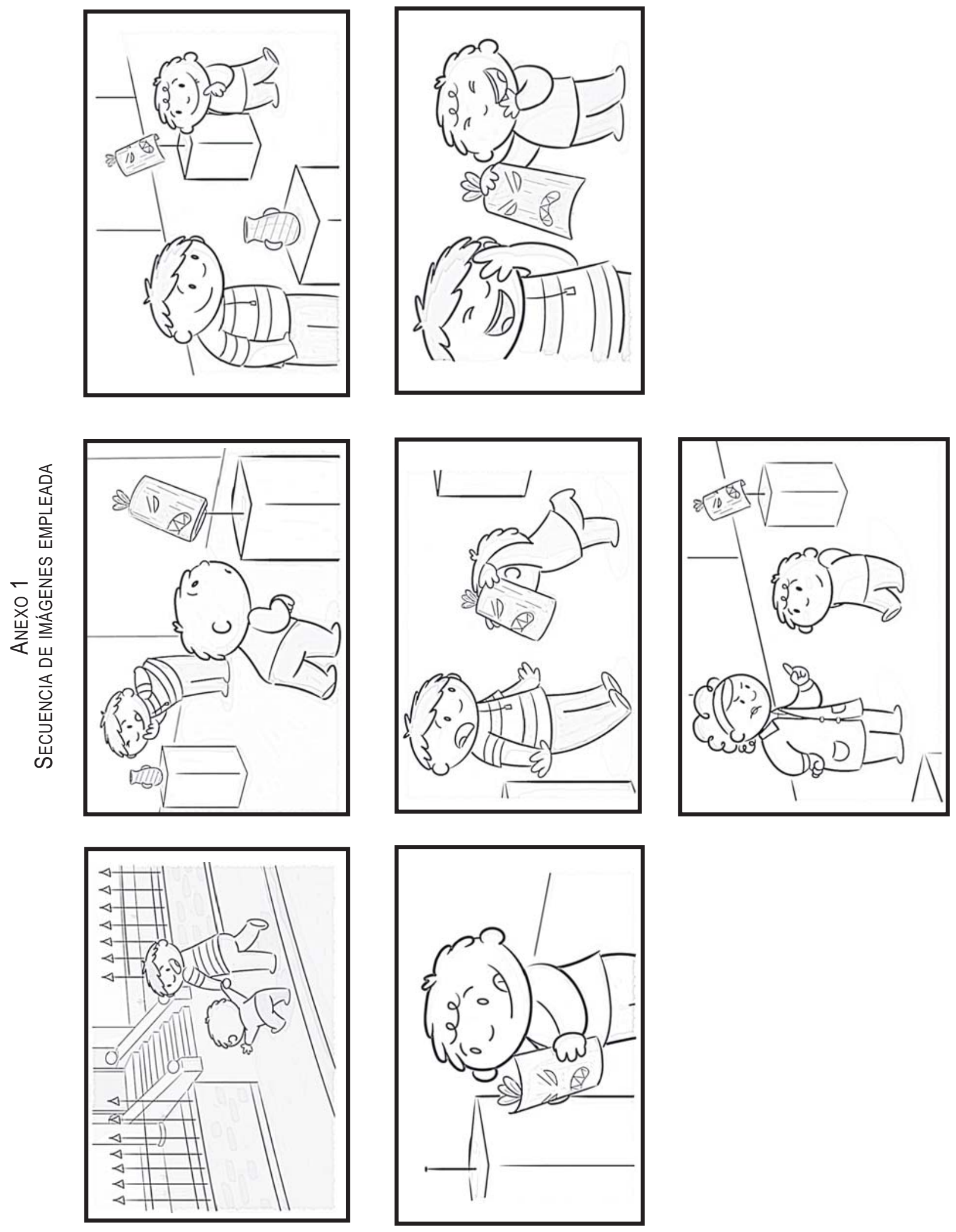
ANEXO 2

CODIFICACIONES EMPLEADAS EN LA TRANSCRIPCIÓN

\{\} comentarios del transcriptor

(()) acciones no verbales

(0.1) pausa: los números entre paréntesis indican el tiempo de la pausa en segundos

- interrupción

/ entonación ascendente

$\backslash$ entonación descendente

${ }^{\circ}$ o tono muy bajo casi inaudible

[mira a ] dirección de la mirada

$==$ superposición

\section{REFERENCIAS BIBLIOGRÁFICAS}

Alam, F. \& Rosemberg, C.R. (2013). El uso de conectores en relatos infantiles de ficción. Diferencias según el contexto interaccional de producción [The use of connectors in children's fictional accounts. Differences depending on the interactional context of production]. Lenguas Modernas, 41, 11-32.

Alam, F., Stein, A. \& Rosemberg, C.R. (2011). “Te explico qué quiere decir", "te digo cómo se llama". Interacciones niño a niño en torno al vocabulario no familiar. ["I tell you what it means", "I tell you how it is call". Child-tochild interactions about non familiar vocabulary]. Bellaterra Journal of Teaching \& Learning Language \& Literature, 4(4), 59-71.

Coll, C. (1991). Aprendizaje escolar y construcción del conocimiento [Scholar learning and knowledge construction]. Buenos Aires: Paidós.

Doise, W., Mugny, G. \& Perret-Clermont, A.N. (1975). Social interaction and the development of cognitive operations. European Journal of Social Psychology, 5, 367-383. http://dx.doi. org/10.1002/ejsp.2420050309

Duranti, A. (1997). Linguistic Antropology. Cambridge: Cambridge University Press.
Eerdemans, S.L., Prevignano, C.L. \& Thibault, P. J. (2003). Language and interaction. Discussions with John J. Gumperz. Amsterdam: Benjamins.

Fawcett, L.M. \& Garton, A.F. (2005). The effect of peer collaboration on children's problem-solving ability. British Journal of Educational Psychology, 75 (Part 2), 157-169. http://dx.doi. org/10.1348/000709904X23411

Fivush, R. (2007). Maternal reminiscing style and children's developing understanding of self and emotion. Clinical Social Work, 35, 37-46.

Fivush, R. \& Haden, C.A. (2005). Parent-child reminiscing and the construction of a subjective self. En B.D. Homer \& C.S. Tamis-Le Monda (Eds.), The development of social cognition and comunication (pp. 315-335). Mahwah, NJ: Erlbaum.

Fivush, R., Haden, C.A. \& Reese, E. (2006). Elaborating on elaborations: Maternal reminscing style and children's socioemotional outcome. Child Development, 77, 1568-1588. http://dx. doi.org/10.1007/s10615-0 06- 0065-1

Forman, E. \& Cazden, C. (1984). Perspectivas vygotskianas en la educación: El valor cognitivo de la interacción entre iguales. Infancia y Aprendizaje, 27-28, 139-157. 
García Sánchez, I. (2010). Serious games: codeswitching and gendered identities in moroccan immigrant girls' pretend play. Pragmatics, 20(4), 523-555.

Gardner, H. \& Forrester, M. (2010). Analysing interactions in childhood. Oxford: WileyBlackwell.

Glaser, B. \& Strauss, A. (1967). The discovery of grounded theory. Chicago: Aldine Publishing Company.

Goodwin, C. (1984). Notes on story structure and the organization of participation. En J.M. Atkinson \& J.C. Heritage (Eds.), Structures of social action: Studies in conversation analysis. (pp. 225-246). Cambridge: University Press Cambridge.

Goodwin, C. (2003). The body in action. En J. Coupland \& R. Gwyn (Eds.), Discourse, the body and identity (pp. 19-42). New York: Palgrave / Macmillan.

Goodwin, C. (2007) Participation, stance and affect in the organization of activities. Discourse \& Society, 18(1) 53-73. http://dx.doi. org/10.1177/0957926507069457

Goodwin, C. \& Heritage, J. (1990). Conversation analysis. Annual Review of Anthropology, 19, 238-307. http://dx.doi.org/10.1146/annurev. anthro.19.1.283

Goodwin, C., Goodwin, M. \& Yaeger-Dror, M. (2002). Multi-modality in girl's game disputes, Journal of Pragmatics, 24(10-11), 1621-1649. http://dx.doi.org/10.1016/S0378-2166(02) 00078-4

Goodwin, M.H. (1997). Byplay: Negotiating evaluation in storytelling. En G.R. Guy, J. Baugh, D. Schiffrin \& Crawford Feagin (Eds.), Towards a social science of language: Papers in honour of William Labov (pp. 77-102). Philadelphia: John Benjamins.

Goodwin, M.H. (2006). The hidden life of girls: Games of stance, status, and exclusion. Malden, MA: Blackwell.
Gumperz, J. (1982) Discourse strategies. Cambridge: Cambridge University Press.

Haden, C.A., Haine, R.A. \& Fivush, R. (1997). Developing narrative structure in parent-child reminiscing across the preschool years. Developmental Psychology, 33, 295-307. http://dx. doiorg/10.1037//0012-1649.33.2.295

Hamo M. \& Blum-Kulka, S. (2007). Apprenticeship in conversation and culture. Emerging sociability in preschool peer talk. En J. Valsiner \& A. Rosa (Eds.), The Cambridge handbook of Sociocultural Psychology (pp. 423-443). Cambridge: Cambridge University Press.

Keenan, E.O. (1979). Conversational competence in children. Journal of Child Language, I, 163-183. http://dx.doi.org/10.1017/S03050 00900000623

Mashburn, A.J., Justice, L.M., Downer, J.T. \& Pianta, R.C. (2009). Peer effects on children's language achievement during pre-kindergarten. Child Development, 80, 686-702. http://dx. doi.org/10.1111/j.1467-8624.2009.01 291.x

Melzi, G. (2000). Cultural variations in the construction of personal narratives: Central American and European American mothers' elicitation styles. Discourse Processes, 30(2), 153177. http://dx.doi.org/10.1207/S15326950DP 3002_04

Melzi, G. \& Caspe, M. (2005). Variations in maternal narrative styles during book reading interactions. Narrative Inquiry, 15(1), 101-125. http://dx.doi.org/10.1075/ni.15.1.06mel

Migdalek, M.J. \& Rosemberg, C.R. (2013). Construcción multimodal de los argumentos de niños pequeños en disputas durante situaciones de juego [Multimodal construction of young children's arguments in disputes during play situations]. Papeles sobre Cultura, Educación y Desarrollo Humano, 9(4), 1-16.

Mugny, G. \& Pérez, J.A. (1988). Psicología social del desarrollo cognitivo [Social Psychology of cognitive development]. Barcelona: Antropos. 
Nelson, K. (1996). Language in cognitive development. Cambridge: Cambridge University Press.

Nelson, K. (2007). Young minds in social worlds. Experience, meaning and memory. Cambridge: Harvard University Press.

Reese, E., Haden, C.A. \& Fivush, R. (1993). Mother-child conversations about the past: Relationships of style and memory over time. Cognitive Development, 8, 403-430. http://dx. doi.org/10.1016/S0885-2014(05)80002-4

Rogoff, B. (1993). Aprendices del pensamiento. El desarrollo cognitivo en el contexto social [Apprenticeship in thinking: Cognitive development in social context.] Barcelona: Paidós.

Rogoff, B. (2003). The cultural nature of human development. New York: Oxford University Press.

Roselli, N.D. (1999). El mejoramiento de la interacción sociocognitiva mediante el desarrollo experiemental de la cooperación auténtica [Improving the sociocognitive interaction with experimental developing of genuine cooperation]. Interdisciplinaria, 16(2), 123-151.

Rosemberg, C.R. (2002). La conversación en el aula: Aportes para una teoría de la enseñanza a través del discurso [The conversation in the classroom: Contributions to a theory of learning through discourse]. Tesis doctoral no publicada. Universidad de Buenos Aires. Buenos Aires, Argentina.

Rosemberg, C.R. \& Alam, F. (2009-). "De niño a niño: Un programa de niños tutores en alfabetización”. Programa de intervención en escuelas y centros comunitarios ["From child to child: A children's tutor literacy program". Intervention program in schools and community centers]. Financiado por: Fundación Care (Alemania), Fundación Save the Children (Argentina), CONICET y SECyT (Argentina).

Rosemberg, C.R., Alam, F. \& Stein, A. (2014). Children interactions in literacy tutoring situa- tions. A study with urban marginalized populations in Argentina. Global Education Review, 1(2), 41-63.

Rosemberg, C.R. \& Menti, A.B. (en prensa). Aspectos teóricos y metodológicos del estudio de la interacción y de las oportunidades para el desarrollo del lenguaje [Theoretical and methodological aspects in the study of interactions and opportunities for language development]. En P. Paoloni, C. Rinaudo \& A.G. Fernández (Eds.), Cuestiones en Psicología Educacional. Perspectivas teóricas, metodológicas y estudios de campo. Sociedad Latina de Comunicación Social: Tenerife, Islas Canarias.

Rosemberg, C.R., Stein, A. \& Alam, F. (2013). At home and at school: Bridging literacy to children from poor rural and urban communities. En K. Hall, T. Cremin, B. Comber y L. Moll (Eds.), International handbook of research in children's literacy, learning and culture (pp. 67-82.) Oxford: Wiley-Blackwell.

Sacks, H., Schegloff, E.A. \& Jefferson, G. (1974). A simple systematics for the organization of turn-taking for conversation. Language, 50, 696-735.

Sinclair, J. \& Clouthard, R.M. (1975). Towards the analysis of discourse. The English used by teachers and pupils. Oxford: Oxford University Press.

Sparks, A., Carmiol, A. \& Ríos, M. (2013). High point narrative structure in mother-child conversations about the past and children's emergent literacy skills in Costa Rica. Actualidades en Psicología, 27(115), 93-111.

Stein, A. \& Rosemberg, C.R. (2012). Redes de colaboración en situaciones de alfabetización familiar con niños pequeños. Un estudio en poblaciones urbano-marginadas de Argentina [Collaboration networks in family literacy situations with preschool children. A study with poor urban population from Argentina]. Interdisciplinaria, 29(1), 95-108. 
Strauss, A. \& Corbin, J. (1991). Basics of qualitative research. Grounded theory. Procedures and technics. Londres: Sage.

Tuson, A. (1995). Análisis de la conversación [Conversation analysis]. Barcelona: Ariel.
Unamuno, V. (2008). Multilingual switch in peer classroom interaction. Linguistics and Education, 19, 1-9. http://dx.doi.org/10.1016/j.linged.2008.01.002

Centro Interdisciplinario de Investigaciones en Psicología Matemática y Experimental Dr. Horacio J.A. Rimoldi (CIIPME) Consejo Nacional de Investigaciones Cientificas y Técnicas (CONICET) Ciudad Autónoma de Buenos Aires República Argentina

Fecha de recepción: 29 de abril de 2014 Fecha de aceptación: 7 de noviembre de 2014 
